\title{
Development of Livestock Feed Mixer
}

\author{
Gosa Bekele
}

\begin{abstract}
Agricultural Machinery and Farm Power Engineering Research Case Team, Oromia Agricultural Research Institute, Asella Agricultural Engineering Research Center, Asella, Ethiopia.
\end{abstract}

DOI: $10.29322 /$ IJSRP.10.10.2020.p10665

http://dx.doi.org/10.29322/IJSRP.10.10.2020.p10665

\begin{abstract}
A livestock feed mixer was designed, constructed and evaluated for its performance using mass of shelled corn as tracer. The machine was tested using a feed composed of 12.63 $\mathrm{kg}$ wheat bran, $12.63 \mathrm{~kg}$ wheat powder, $12.63 \mathrm{~kg}$ faba bean bran, $10.1 \mathrm{~kg}$ cotton cake, $1.18 \mathrm{~kg}$ of salt, $0.84 \mathrm{~kg}$ molasses and $2 \mathrm{~kg}$ ungrounded corn replicated thrice at four mixing durations of 5, 10,15 and 20 minutes and paddle shaft speed of 480 , and 580 $\mathrm{rpm}$. The effectiveness of mixing was assessed on the basis of mass of shelled corn, and percent of coefficient of variation (CV $\%)$ and degree of mixing of sample collected at the end of each test. The best values of coefficient of variation (13.09 \%) and degree of mixing $(86.91 \%)$ were obtained at mixing paddler shaft speed of $580 \mathrm{rpm}$ and mixing time of 10 minutes. Hence, it can be concluded that the machine, the prototype livestock feed mixer, should be operated at speed of $580 \mathrm{rpm}$ with maximum holding/mixing time of 10 in order to make the owning and operating of the machine productive (in terms of $\mathrm{kg} / \mathrm{hr}$ ) and economical (in terms labour and energy cost birr/kg of mixed quality feed. The capacity of the machine is about four quintals per hour or 32 quintals per day of 8 hours of work.
\end{abstract}

Index Terms- Livestock, livestock feeds and feed mixer

\section{INTRODUCTION}

L ivestock is an integral part of the agriculture and the contribution of live animals and their products to the agricultural economy accounts for $40 \%$, excluding the values of draught power, manure and transport of people and products (Winrock International, 1992). Ethiopia holds the largest livestock population in Africa estimated at about 43.1 million heads of cattle, 23.6 million sheep, 18.6 million goats, 4.5 million donkeys, 1.7 million horses, 0.33 million mules, 34.2 million chicken and 4.9 million beehives (CSA, 1996). Similarly, contributions of livestock to cash income of the smallholders account for up to $87 \%$ and, subsistence of some pastoral communities is entirely based on livestock and livestock products. Despite these roles, the productivity of livestock in general is low and compared to its huge resource its contribution to the national economy is below expected. Zegeye (2003) indicated that feed shortage, poor genetic potential for productive traits, poor health care and management practices are the major contributors to the low productivity.

Livestock feed is the general term for food given to farm animals. The regular supply of food to farm animals is very essential to a healthy and productive life. Feed production for livestock, poultry or aquatic life involves a range of activities, which include grinding, mixing, pelleting and drying operations. Different types of machinery needed for the production of various types of feeds include; grinders, mixers, elevators and conveyors, mixer, extruders, cookers, driers, fat sprayers and steam boilers (New, 1987). The mixing operation in particular, is of great importance, since it is the means through which two or more ingredients that form the feed are interspersed in space with one another for the purpose of achieving a homogenous mixture capable of meeting the nutritional requirements of the target livestock, poultry or aquatic life being raised (Balami, et al., 2013).

Feed mixing can be done either manually or mechanically. The manual method of mixing feed entails the use of shovel to intersperse the feed's constituents into one another on open concrete floors. This method is generally characterized by low output, less efficient, labor intensive and may prove unsafe, hence, hazardous to the health of the intended animals.

A wide variety of mixers are available for use in mixing components, the selection of which depends mainly on the phase or phases the components exists such as solid, liquid or gaseous phases. But in Ethiopia, different organizations and research centers have imported and or developed various types of animal feed choppers and millers. But as their efforts missed mixer part of the process, the small scale farmers are forced to use the manual method of chopped/ milled feed. Therefore, this activity was initiated with objectives of developing and evaluating a mixer machine capable of mixing livestock feed constituents effectively and uniformly for small and medium scale farmers.

\section{MATERIALS AND METHODS}

\subsection{Materials}

The raw materials used for production of livestock feed mixer was steel shaft having diameters of 35 and $20 \mathrm{~mm}, 2 \mathrm{~mm}$ and $1.5 \mathrm{~mm}$ sheet metal, $4 \mathrm{~mm} * 40 \mathrm{~mm} * 40 \mathrm{~mm}$ angle iron and $3 \mathrm{~mm} * 30 \mathrm{~mm} * 30 \mathrm{~mm}$ size square pipe, $5 \mathrm{~mm} \times 50 \mathrm{~mm} \times 50$ $\mathrm{mm}$ angle iron, $10.5 \mathrm{hp}$ diesel engine, pulleys having diameters of $460 \mathrm{~mm}, 180 \mathrm{~mm}$ and $140 \mathrm{~mm}$, UCP bearings of 204 and 6205, different sizes of bolt and nut and hinges.

\subsubsection{Instruments}

In order to measure different size and dimension of construction and testing materials measuring tape, digital balance, tachometer, caliper, small bags and others were used during construction and data collection on the field.

\subsection{Methods}

\subsubsection{Description of Livestock Feed Mixer}

This publication is licensed under Creative Commons Attribution CC BY. 
A horizontal livestock feed mixer was developed and constructed in AAERC. The mixer consists of the essential component parts like: feeding unit, mixing unit, power driving unit and feed discharging unit. The mixing section has half cylindrical shape in the lower side and rectangular shape on the upper side. The mixing chamber is provided with centrally based horizontal and vertical acting auger and paddles that operate inside a mixing chamber. Feeding unit is attached to the mixing unit on the upper left side while discharging part is attached in the lower right side. All these machine components were connected to each other with bolt and nut and welding on the main frame (Figure 1).

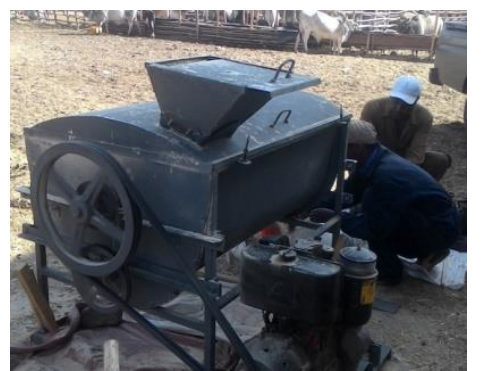

Figure 1: The developed livestock feed mixer

\subsubsection{Working Principle of the Machine}

Feed ingredients are introduced into the mixer via a feeding unit located at the upper part of the mixing compartment. Material introduction into the mixer is in order of quantity, with the bulkier material among the feed components being introduced into the machine first. The diesel engine used to drive the mixer for mixing livestock feed ingredients is on. The rotating action of the paddles located on the centrally rotating shaft and auger moves the feed ingredients front, back, down, up and sideways. After a thorough mixing was achieved, the discharge chute was opened to allow the flow of mixed feed material out of the mixer.

\subsubsection{Part Description}

The developed livestock feed mixer consisted of the following major parts: a mixing chamber, a mixing unit, frame, feeding hopper, feed outlet, engine sit, drive and driven Pulleys, screw (auger) conveyor, bearing, steel shaft, and V-belt.

\section{a) Feeding hopper construction}

Feeding hopper has a trapezoidal shape located at upper end of the prototype mixer. The inclination of the feeding trough from the vertical or horizontal was decided by considering the largest angle of repose of the materials which was $60^{\circ}$.

\section{b) Mixing chamber}

The mixing chamber has a half cylindrical shape in the lower and rectangular shape on the upper part by rolling and bending. This mixing chamber was made from $2 \mathrm{~mm}$ sheet metal which was cut, rolled and welded together with the standing frames.

\section{c) Feed chute construction}

An opening of $150 \times 70 \mathrm{~mm}$ size, provided at the bottom end of the mixing chamber, is connected to the discharge chute. The chute has a shutter mechanism used for closing and opening the gate in order to facilitate discharge of the material after mixing or maintain the material within the chamber during mixing.

\section{d) Frame construction}

The frame was constructed from square pipe of $30 \times 30 \times 3$ $\mathrm{mm}$ and $5 \times 50 \times 50 \mathrm{~mm}$ angle iron considering the rated strength and stability during service. The frame has height of $900 \mathrm{~mm}$, width of $840 \mathrm{~mm}$ and length of $1210 \mathrm{~mm}$.

\section{e) Mixing unit}

A horizontal axis screw and paddler were operated inside a mixing chamber to effect the mixing process. As per the recommendation of Balami et al. (2013), who designed, manufactured and evaluated an animal feed mixer, a screw with helix of uniform diameter of $145 \mathrm{~mm}$ and a pitch of $100 \mathrm{~mm}$ was selected and all the necessary design analyses were made on the basis of the dimensions stated above.

\subsection{Selection of Drive and Transmission \\ 1.3.1. Selection of pulley diameters}

The diameters are selected based on the need to reduce the diesel engine speed to the required paddle type horizontal feed mixer shaft. It is given by the following equation

$D_{1} \times N_{1}=D_{2} \times N_{2}$

Where: D1 = Diameter of driving pulley in $(\mathrm{mm}), \mathrm{D} 2=$ Diameter of driven pulley in $(\mathrm{mm}), \mathrm{N} 1=$ Speed of driving pulley in $(\mathrm{rpm}), \mathrm{N} 2=$ Speed of driven pulley in $(\mathrm{rpm})$

\subsubsection{Selection of the drive}

V-belt and pulley arrangements were adopted in this work to transmit power from the Diesel engine to the shaft of the paddle type horizontal feed mixing shaft. The main reasons for adopting the v-belt drive is its flexibility, simplicity, and low maintenance costs. Additionally, the $\mathrm{v}$ - belt has the ability to absorb shocks there by mitigating the effect of vibratory forces (Khurmi and Gupta, 2005).

\subsubsection{Determination of belt contact angle}

The belt contact angle and angles of wrap for smaller and larger pulley is given by the following equation (Khurmi and Gupta, 2005).

$\varphi=\operatorname{Sin}^{-1}\left(\frac{R-r}{C}\right)$

$\alpha_{1}=180-2 \operatorname{Sin}^{-1}\left(\frac{R-r}{C}\right)$

$\alpha_{2}=180+2 \operatorname{Sin}^{-1}\left(\frac{R-r}{C}\right)$

Where: $\mathrm{R}=$ radius of driven pulley, $\mathrm{mm} ; \mathrm{r}=$ radius of driving pulley, $\mathrm{mm} ; \varphi=$ belt contact angle, deg; $\alpha_{1}=$ angle of wrap for the driving pulley, deg; $\alpha_{2}=$ angle of wrap for the driven pulley, $\mathrm{deg} ; \mathrm{C}=$ is the center distance between the two center pulleys.

\subsubsection{Determination of belt length}

The length of belt appropriate to drive the system is calculated using the equation given below by Shigley and Mischike (2001).

$L=2 C+\frac{\pi}{2}\left(D_{2}+D_{1}\right)+\frac{\left(D_{2}-D_{1}\right)^{2}}{4 C}$ 
Where: $\mathrm{L}=$ belt length, $\mathrm{m} ; \mathrm{C}=$ center distance between pulleys, $\mathrm{m} ; \mathrm{D}_{2}=$ pitch diameter of driven pulley, $\mathrm{m} ; \mathrm{D}_{1}=$ Pitch diameter of driver pulley, $\mathrm{m}$.

Speed of the belt was calculated by using the equation as given by Khurmi and Gupta (2005).

$v=\frac{\pi D_{1} N_{1}}{60}$

\subsubsection{Bearing selection}

Bearings selection was made in accordance to American Society of Mechanical Engineers (ASME) standard as given by Hall et al. (1988).

\subsubsection{Determination of belt tensions}

To determine tensions on the tight and slack sides of the belt the following equations is used (Khurmi and Gupta, 2005).

$T_{1}=T-T_{c}$

$T=\sigma_{\max } a$

$T_{c}=m v^{2}$

Where: $T_{c}$ and $T=$ the centrifugal and maximum tension of a belts $(\mathrm{N}) ; \mathrm{T}_{1}$ and $\mathrm{T}_{2}=$ tension in the tight and slack sides $(\mathrm{N}), \sigma_{\max }=$ maximum safe normal stress $\left(\mathrm{N} / \mathrm{mm}^{2}\right) ; a=$ is cross sectional area of belt $\left(\mathrm{mm}^{2}\right), m=$ mass per unit length of belt $(\mathrm{kg} / \mathrm{m}) ; v=$ is speed of belt $(\mathrm{m} / \mathrm{s})$, Values of $\sigma_{\max }, a$ and $m$ are taken from standard tables.

Tensions on the tight and slack sides of the belt will be estimated using the equation given by Khurmi and Gupta, (2005):

$\frac{T_{1}-T_{c}}{T_{2}-T_{c}}=e^{\mu \alpha_{1} \operatorname{cosec} \frac{\beta}{2}}$

Where: $\mu=$ coefficient of friction between a belt and a pulley

from design book $0.25, \beta=$ groove angle $40^{\circ}, \alpha_{1}=$ angle of wrap on driver pulley

According to Khurmi and Gupta (2005) torsional moment $\left(\mathrm{T}_{\mathrm{r}}\right)$ due to belt tensions was determined using the following equation.

$T_{r}=\left(T_{1}-T_{2}\right) \frac{D_{2}}{2}$

where: $T_{1}=$ tension on tight side of a belt $(\mathrm{N}), \mathrm{T}_{2}=$ tension on slack side of a belt $(\mathrm{N}), D_{2}=$ is the diameter of driven pulley (mm).

\subsubsection{Determination of Screw Shaft Diameter}

According to American Society of Mechanical Engineers (ASME) code (ASME, 1995) for the design of solid transmission shafts, the maximum permissible working stresses in tension or compression may be taken as $112 \mathrm{MPa}$ for shafts without allowance for keyways and $84 \mathrm{MPa}$ for shafts with allowance for keyways. The maximum permissible shear stress may be taken as $56 \mathrm{MPa}$ for shafts without allowance for key ways and $42 \mathrm{MPa}$ for shafts with allowance for keyways. According to maximum shear stress theory, equivalent twisting moment $\left(\mathrm{T}_{\mathrm{e}}\right)$ and that of a mixer shaft diameter $(d)$ is determined as follow:

$$
T_{e}=\sqrt{\left(M K_{b}\right)^{2}+\left(T K_{t}\right)^{2}}
$$

According to maximum normal stress theory, equivalent bending moment is given as:

$$
\begin{aligned}
& M_{e}=\frac{1}{2}\left(K_{b} M+\sqrt{\left(K_{b} M\right)^{2}+\left(K_{t} T\right)^{2}}\right) \\
& M_{e}=\frac{\pi \sigma_{b} d^{3}}{32 \times f_{S}}
\end{aligned}
$$

Where: where: $\quad \mathrm{T}_{\mathrm{e}}=$ equivalent twisting moment, $\mathrm{Nm} ; \mathrm{M}=$ maximum bending moment, $\mathrm{Nm} ; \mathrm{M}_{\mathrm{e}}=$ equivalent bending moment, $\mathrm{Nm} ; \sigma_{\mathrm{b}}=$ maximum allowable normal stress, 84 $\mathrm{MPa} ; \mathrm{T}=$ twisting moment, $\mathrm{Nm} ;=$ maximum allowable shear stress, $42 \mathrm{MPa}$; fs = factor of safety assume $2, \mathrm{~d}=$ diameter of mixer shaft, m.For rotating shafts, with load suddenly applied and minor shock, combined shock and fatigue factor were applied to bending and torsional moment as recommended; the values used were $\mathrm{K}_{\mathrm{b}}=1.20$ to 2.00 , and $\mathrm{K}_{\mathrm{t}}=1.00$ to 1.50 , (Khurmi and Gupta (2005). Therefore, the values of $K_{b}=1.20$ and $\mathrm{K}_{\mathrm{t}}=1.00$ were used in this work.

\subsection{Performance Test}

Performance testing of the mixer was targeted at evaluating its ability to mix feed components, duration of mixing and rate of discharge. At the onset of the test, $37.89 \mathrm{~kg}$ of wheat bran, $37.89 \mathrm{~kg}$ of wheat flour, $37.89 \mathrm{~kg}$ of faba bean bran, 30.30 $\mathrm{kg}$ of cotton cake, $3.54 \mathrm{~kg}$ of salt, $2.52 \mathrm{~kg}$ of molasses and 6.00 $\mathrm{kg}$ of ungrounded maize as tracer were divided into three equal measures of $12.63 \mathrm{~kg}$ of wheat bran, $12.63 \mathrm{~kg}$ of wheat flour, $12.63 \mathrm{~kg}$ of faba bean bran, $10.10 \mathrm{~kg}$ of cotton cake, $1.18 \mathrm{~kg}$ of salt, $0.84 \mathrm{~kg}$ of molasses and $2.00 \mathrm{~kg}$ of ungrounded maize, and the mixer's performance test was conducted and replicated thrice according to the standard test procedure for farm batch feed mixers developed by ASAE, (R2006) and Ibrahim and Fasasi (2004). Four mixing durations of $5 \mathrm{~min}, 10 \mathrm{~min}, 15 \mathrm{~min}$ and 20 min and two mixing speed $480 \mathrm{rpm}$ and $580 \mathrm{rpm}$ where considered in the cause of conducting the tests. At the end of each test run, ten samples of $1 \mathrm{~kg}$ were drawn from the mixed components and the coefficient of variation among mixed samples and mixing levels, were computed using the expressions below as given by Ibrahim and Fasasi (2004):

$$
\begin{aligned}
& C V=\frac{S D}{y} \times 100 \\
& \bar{y}=\frac{\sum y_{i}}{n}
\end{aligned}
$$

$$
\begin{aligned}
& S D=\sqrt{\sum \frac{(y-y)^{2}}{(n-1)}} \\
& D M=100-\% C V
\end{aligned}
$$

Where: $\mathrm{CV}=$ percent coefficient of variation, $\mathrm{DM}=$ percent degree of mixing, $\mathrm{SD}=$ standard deviation, = mean, $\sum=$ sum, $\mathrm{y}_{\mathrm{i}}=$ individual $y_{\text {sample analysis }}$ results, $\mathrm{n}=$ total number of samples

\subsection{Experimental Design and Statistical Analysis}


The experimental design is randomized complete design with three replications. Treatments consisted of factorial combinations of two mixing speeds (480 and $580 \mathrm{rpm}$ ) and four mixing times $(5,10,15$ and $20 \mathrm{~min})$. Data was subjected to analysis of variance following a procedure appropriate to the design. Analysis was done using GenStat $15^{\text {th }}$ edition software. The treatment means that were different at $5 \%$ level of significance was separated by using LSD.

\section{RESULTS AND DISCUSSION}

The necessary design parameters needed for the development of a horizontal livestock feed mixer were considered in depth. Proper shaft, paddler and auger design analysis was carried out on the machine to avoid failure on both paddler shaft and auger shaft. A prototype of the livestock feed mixer was manufactured using materials available on market, with the AAERC's workshop technicians. Its performance tests were carried out at four mixing times and two mixing speeds (paddler shaft speeds, rpm) to evaluate the mixing performance of the prototype feed mixer.

Table 1: Technical Characteristics of the Mixing Machine

\begin{tabular}{|c|c|c|}
\hline No. & Technical characteristics & $\begin{array}{l}\text { Determined and } \\
\text { selected values }\end{array}$ \\
\hline 1 & $\begin{array}{l}D_{2}=\text { Diameter of pulley for the } \\
\text { mixing paddler }\end{array}$ & $460 \mathrm{~mm}$ \\
\hline 2 & $\begin{array}{l}\mathrm{C}_{1}=\text { center distance between larger } \\
\text { pulley }\end{array}$ & $869 \mathrm{~mm}$ \\
\hline 3 & $\mathrm{~L}_{1}=$ length of larger belt & $2710 \mathrm{~mm}$ \\
\hline 4 & $v=$ Speed of the belt $\mathrm{m} / \mathrm{s}$ & $13.96 \mathrm{~m} / \mathrm{s}$ \\
\hline 5 & $\begin{array}{l}\mathrm{T}_{1}=\text { tension of belts on the tight side } \\
\text { of larger pulley }\end{array}$ & $298.10 \mathrm{~N}$ \\
\hline 6 & $\begin{array}{l}\mathrm{T}_{2}=\text { tension of belts on the slag side } \\
\text { of larger pulley }\end{array}$ & $165.18 \mathrm{~N}$ \\
\hline 7 & $\begin{array}{l}\mathrm{T}_{12}=\text { tension of belts on the tight } \\
\text { side of smaller pulley }\end{array}$ & $166.88 \mathrm{~N}$ \\
\hline 8 & $\begin{array}{l}\mathrm{T}_{22}=\text { tension of belts on the tight } \\
\text { side of smaller pulley }\end{array}$ & $88.80 \mathrm{~N}$ \\
\hline 9 & $\begin{array}{l}T_{c} \text { and } T=\text { the centrifugal and } \\
\text { maximum tension of a belts on } \\
\text { larger pulley }\end{array}$ & $\begin{array}{l}42.10 \quad \mathrm{~N} \quad \text { and } \\
340.20 \mathrm{~N}\end{array}$ \\
\hline 10 & $\begin{array}{l}T_{c} \text { and } T=\text { the centrifugal and } \\
\text { maximum tension of a belts on } \\
\text { smaller pulley }\end{array}$ & $\begin{array}{l}3.22 \mathrm{~N} \text { and } 170.10 \\
\mathrm{~N}\end{array}$ \\
\hline 11 & $\begin{array}{l}\mathrm{W}_{\mathrm{lp}}=\text { weight of larger paddler shaft } \\
\text { pulley }\end{array}$ & $103.01 \mathrm{~N}$ \\
\hline 12 & $\begin{array}{l}\mathrm{W}_{\mathrm{sp}}=\text { weight of smaller paddler } \\
\text { shaft pulley }\end{array}$ & $23.54 \mathrm{~N}$ \\
\hline 13 & $\rho=$ density of feed & $621.38 \mathrm{~kg} / \mathrm{m}^{3}$ \\
\hline 14 & $\begin{array}{l}\mathrm{W}_{\mathrm{p}}=\text { weight of paddles found on } \\
\text { shaft }\end{array}$ & $62.59 \mathrm{~N}$ \\
\hline 15 & $\begin{array}{l}\mathrm{R}_{\mathrm{VAy}}=\text { Vertical reaction force at } \\
\text { bearing close to pulleys }\end{array}$ & $1467.67 \mathrm{~N}$ \\
\hline 16 & $\begin{array}{l}\mathrm{R}_{\mathrm{VBy}}=\text { Vertical reaction force at } \\
\text { bearing far from pulleys }\end{array}$ & $117.07 \mathrm{~N}$ \\
\hline 17 & $\mathrm{R}_{\mathrm{HAx}}=$ Horizontal reaction force at & $84.10 \mathrm{~N}$ \\
\hline
\end{tabular}

\begin{tabular}{|c|c|c|}
\hline & bearing close to pulleys & \\
\hline 18 & $\begin{array}{l}\mathrm{R}_{\mathrm{HBx}}=\text { Horizontal reaction force at } \\
\text { bearing far from pulleys }\end{array}$ & $7.47 \mathrm{~N}$ \\
\hline 19 & $\begin{array}{l}\mathrm{BM}_{\mathrm{VCmax}}=\text { Vertical maximum } \\
\text { bending at the center of mixing } \\
\text { hopper say } \mathrm{C}\end{array}$ & $117.71 \mathrm{Nm}$ \\
\hline 20 & $\begin{array}{l}\mathrm{BM}_{\mathrm{HCmax}}=\text { Horizontal maximum } \\
\text { bending at the center of mixing } \\
\text { hopper say } \mathrm{C}\end{array}$ & $9.32 \mathrm{Nm}$ \\
\hline 21 & $\begin{array}{l}\mathrm{T}_{\mathrm{r}}=\text { torsional moment due to belt } \\
\text { tensions }\end{array}$ & $59.91 \mathrm{Nm}$ \\
\hline 22 & $\mathrm{M}=$ total bending moment & $118.08 \mathrm{Nm}$ \\
\hline 23 & $\mathrm{~T}_{\mathrm{e}}=$ equivalent twisting moment & $153.43 \mathrm{Nm}$ \\
\hline 24 & $\mathrm{M}_{\mathrm{e}}=$ equivalent bending moment & $147.56 \mathrm{Nm}$ \\
\hline 25 & $\mathrm{~d}=$ Paddler shaft diameter & $35 \mathrm{~mm}$ \\
\hline
\end{tabular}

Table 2 gives the average weight of ungrounded corn recovered from each of the 10 samples drawn from the mass of mixed components after a mixing period of 5, 10, 15, and $20 \mathrm{~min}$ in respect of the three replicated tests at paddler shaft speed of $480 \mathrm{rpm}$.

Table 2. Prototype livestock feed mixer performance at paddler shaft speed of $480 \mathrm{rpm}$ and mixing time of $5,10,15$ and 20 minutes

\begin{tabular}{|l|l|l|l|}
\hline $\begin{array}{l}\text { Mixing } \\
\text { time } \\
\text { (Minute } \\
)\end{array}$ & $\begin{array}{l}\text { Mean weight of } \\
\text { ungrounded Corn/ } \\
\text { Tracer }(\text { Kg) }\end{array}$ & $\begin{array}{l}\text { Mean } \\
\text { Coefficient of } \\
\text { Variation (CV } \\
\text { \%) }\end{array}$ & $\begin{array}{l}\text { Degree of } \\
\text { Mixing } \\
\text { (DM \%) }\end{array}$ \\
\hline 5 & 0.0214 & 36.85 & 63.15 \\
\hline 10 & 0.0207 & 20.75 & 79.25 \\
\hline 15 & 0.0226 & 19.20 & 80.80 \\
\hline 20 & 0.021 & 15.91 & 84.09 \\
\hline
\end{tabular}

The average weights of ungrounded corn recovered from the three replicates are $0.0214 \mathrm{~kg}, 0.0207 \mathrm{~kg}, 0.0226 \mathrm{~kg}$ and $0.0210 \mathrm{~kg}$ with corresponding coefficient of variability $(\mathrm{CV})$ of $36.85 \%, 20.75 \%, 19.20 \%$ and $15.91 \%$, during mixing times of 5, 10, 15 and 20 minutes respectively. From Table 2, it can be noted that at the mixing time of 20 minutes, the percentage coefficient variation and degree of mixing values were15.91 and $84.09 \%$ respectively. The values indicate that as the time of holding increases the percentage of coefficient variation decreases while percentage degree of mixing increases.

Table 3 gives values of performance indicators such as percentage mean mass of ungrounded corn, coefficient of variation, and degree of mixing at the mixing paddler shaft speed of $580 \mathrm{rpm}$ and different mixing time in minutes.

Table 3. Prototype livestock feed mixer performance at paddler shaft speed of $580 \mathrm{rpm}$ and mixing time of 5, 10, 15 and 20 minutes.

\begin{tabular}{|l|l|l|l|}
\hline $\begin{array}{l}\text { Mixing } \\
\text { time }\end{array}$ & $\begin{array}{l}\text { Mean weight of } \\
\text { ungrounded Corn/ }\end{array}$ & $\begin{array}{l}\text { Mean } \\
\text { Coefficient of }\end{array}$ & $\begin{array}{l}\text { Degree of } \\
\text { Mixing }\end{array}$ \\
\hline
\end{tabular}

This publication is licensed under Creative Commons Attribution CC BY. 


\begin{tabular}{|l|l|l|l|}
\hline $\begin{array}{l}\text { (Minute } \\
\text { Tracer (Kg) }\end{array}$ & $\begin{array}{l}\text { Variation (CV } \\
\text { \%) }\end{array}$ & (DM \%) \\
\hline 5 & 0.0144 & 42.42 & 57.58 \\
\hline 10 & 0.0184 & 13.09 & 86.91 \\
\hline 15 & 0.0177 & 26.12 & 73.88 \\
\hline 20 & 0.0194 & 26.76 & 73.24 \\
\hline
\end{tabular}

The mean weight of ungrounded corn, and percentage coefficient of variation and degree of mixing of the prototype machine at mixing paddler speed $580 \mathrm{rpm}$ and mixing time of 5, 10,15 , and 20 minutes were found to be $0.0144,42.42$ and $57.58,0.0184,13.09$, and $86.91,0.0177,26.12$ and 73.88 and $0.0194,26.76$ and 89.73.24, respectively. From Table 3, it can be seen that, at the mixing paddler shaft speed of $580 \mathrm{rpm}$, mixing time of 10 minute resulted in percentage coefficient variation of $13.09 \%$. The value of coefficient variations obtained at mixing times 10 minute is within upper boundary of rating as indicated by Herrman and Behnke (1994) (values of percentage coefficient of variations $<10,10-15,15-20$ and $>20$ are rated excellent, good, fair and poor, respectively, in terms of uniformity/thoroughness of mixing). Hence, the mixing uniformity was superior at the combination of $580 \mathrm{rpm}$ and 10 minutes of mixing time.

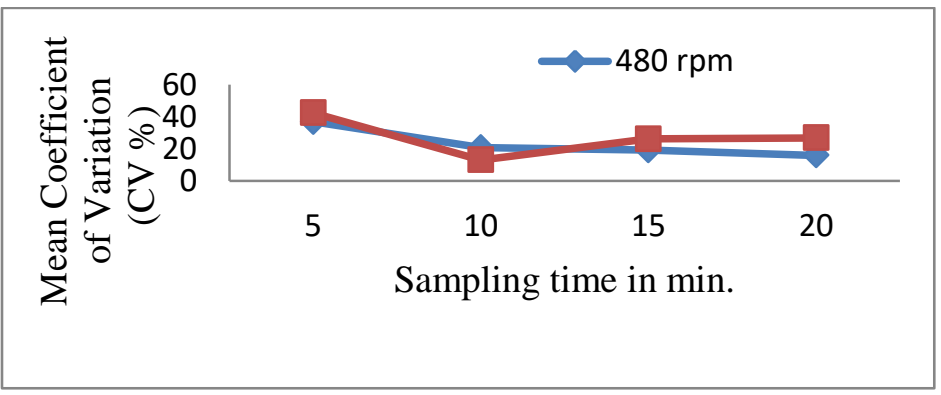

Figure 2.Effect of $\mathrm{n}$ sampling time and $\mathrm{rpm}$ on the coefficient of variation for the mixer using weight of ungrounded corn as the tracer (based on Tables 1 and2)

From the above figure we observe that as the time of mixing and speed of the paddler increases percent coefficient of variation decreases and percent degree of mixing increases up to some extent and then vice versa.

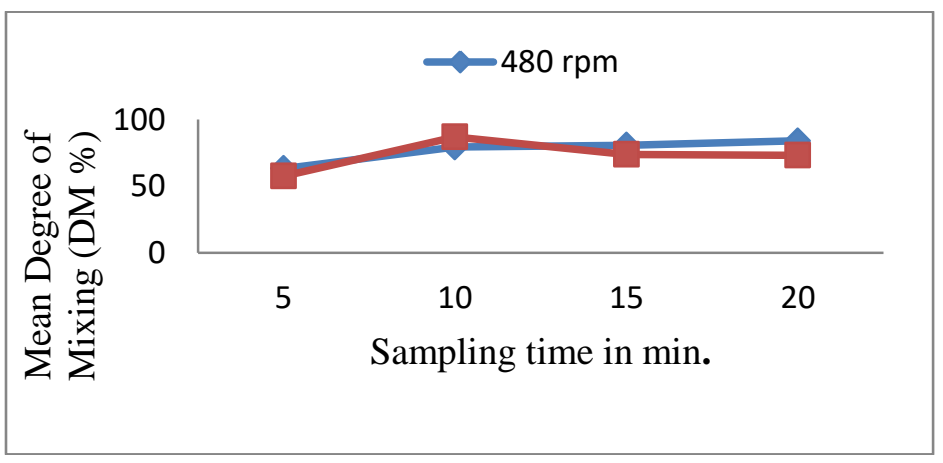

Figure 3.Effect of $\mathrm{n}$ sampling time and rpm on the degree of mixing for the mixer using weight of ungrounded corn as the tracer (based on Tables 2 and 3)
From figure 3 we observe that as the time of mixing and speed of the paddler increasing mean percent of mixing increases up to the optimum value attained. When the speed of paddler shaft is $480 \mathrm{rpm}$ and duration of mixing time increases degree of mixing increases to some optimum level but it is not economical in terms of cost.

Results of the analysis of variance (ANOVA) presented in Table 4 revealed that the mixing paddler shaft speed and the interaction with mixing time had no significant effect while mixing time had significant effect $(p=0.05)$ on coefficient of variation. Table 4shows the effect of mixing paddler shaft speed, mixing time and the combined effect of screw shaft speed with mixing/holding time on mean percent of coefficient of variation $(\mathrm{CV} \%)$.

\section{Table 3. Paddler shaft speed, mixing time and their interaction on means of $\% \mathrm{CV}$}

\begin{tabular}{|c|c|c|c|c|c|c|c|}
\hline \multirow[t]{12}{*}{$\begin{array}{l}\text { Paramete } \\
\text { r }\end{array}$} & \multicolumn{3}{|c|}{$\begin{array}{l}\text { Paddler } \quad \text { shaft } \\
\text { speed }(R), \text { rpm }\end{array}$} & \multicolumn{2}{|c|}{$\mathrm{CV} \%$} & $\begin{array}{l}\text { LSD } \\
5 \%\end{array}$ & SE(M \\
\hline & \multicolumn{3}{|c|}{480} & \multicolumn{2}{|l|}{$22.8^{\mathrm{a}}$} & \multirow[b]{2}{*}{$\begin{array}{l}12.1 \\
6\end{array}$} & \multirow[b]{2}{*}{4.01} \\
\hline & \multicolumn{3}{|c|}{580} & \multicolumn{2}{|l|}{$27.2^{\mathrm{a}}$} & & \\
\hline & \multicolumn{3}{|c|}{ Mixing time, min } & & \multirow{5}{*}{$\begin{array}{l}17.1 \\
9\end{array}$} & \multirow{5}{*}{5.67} \\
\hline & \multicolumn{3}{|c|}{5} & \multicolumn{2}{|l|}{$39.7 \mathrm{a}$} & & \\
\hline & \multicolumn{3}{|l|}{10} & \multicolumn{2}{|l|}{$16.9^{\mathrm{b}}$} & & \\
\hline & \multicolumn{3}{|l|}{15} & \multicolumn{2}{|l|}{$22.8^{\mathrm{ab}}$} & & \\
\hline & 20 & & & $20.7^{\mathrm{b}}$ & & & \\
\hline & \multicolumn{5}{|c|}{ Interaction $\mathrm{R} * \mathrm{~T}$} & \multirow{4}{*}{$\begin{array}{l}24.3 \\
1\end{array}$} & \multirow{4}{*}{8.02} \\
\hline & & $\begin{array}{l}5 \\
\min \end{array}$ & $\begin{array}{l}10 \\
\min \end{array}$ & $\begin{array}{l}15 \\
\min \end{array}$ & $\begin{array}{l}20 \\
\min \end{array}$ & & \\
\hline & $\begin{array}{l}48 \\
0 \\
\mathrm{rp} \\
\mathrm{m}\end{array}$ & $36.7^{\mathrm{a}}$ & $20.7^{\mathrm{a}}$ & $19.3^{\mathrm{a}}$ & $14.7^{\mathrm{b}}$ & & \\
\hline & $\begin{array}{l}58 \\
0 \\
\mathrm{rp} \\
\mathrm{m}\end{array}$ & $42.7^{\mathrm{a}}$ & $13.1^{\mathrm{b}}$ & $26.3^{\mathrm{a}}$ & $26.7^{\mathrm{a}}$ & & \\
\hline
\end{tabular}

Means with similar letters indicated that there is no significant difference between them at 5\% of significance level.

\subsection{Conclusion and Recommendation \\ 1.6.1. Conclusion}

The livestock feed mixing machine was successfully designed, developed and tested. A mixing performance of up to $86.91 \%$ was attained in 10 minutes of operation and emptying of mixed materials from the mixer was accomplished in 5 minutes with the mixer at full capacity with small amount of feed left. The average value of coefficient of variation for the three replicates was $13.09 \%$. The salient implication of the result of this study is that the mixing machine developed from available materials on the market is effective, simple and easy to maintain. The mixer can mix about four quintals per hour.

\subsubsection{Recommendation}

In order to use this machine the user must consider the following recommendations. One of the recommendation is that, all the ingredients used for livestock feed preparation must be chopped and milled based on the size of their recommendation. 
The ingredients that have larger volume and density must be filled first and then the next continued in the same manner. The machine is used for all stock raisers. The machine can mix uniformly when the ingredients is not filled at its full level and below half.

\section{REFERENCES}

[1] ASAE Standards, (ASAE S380 DEC1975 R2006). Test Procedure to Measure Mixing Ability of Portable Farm Batch Mixers, pp. 261 - 262.

[2] ASME, 1995. Design of Transmission Shaft. American Society of Mechanical Engineering, New York, USA.

[3] Balami, A. A., D. Adgidzi and A. Mua'zu, 2013. Development and testing of an animal feed mixing machine. International Journal of Basic and Applied Science, Jan 2013, 1(3): 491-503.

[4] CSA, 1996. Livestock resource and production statistics in Ethiopia Central Statistics Authority (CSA). In proc. fourth conference of the Ethiopian Society of Animal production. (ESAP) 18-19 April 1996. Addis Ababa, Ethiopia, pp: 11-29

[5] Hall, H., M. S. Holowenk and G. L. Herman, 1988. Theory and Problems of Machine Design, Shaum Outline Series, MacGraw-Hill Book Company, New York.

[6] Herman, T. and K. Behnke, 1994. Testing Mixer Performance.MF1172.Kansas State University Agricultural Experiment Station and Cooperative Extension Service Bulletin.Kansas State University, Manhattan, KS.
[7] Ibrahim, S. O. and M. B. Fasasi (2004). Design and development of a portable feed mixer for small-scale poultry farmers. Proc. NIAE 26, Nov. 28- Dec. 2, Ilorin.

[8] Khurmi, R. S. and J. K. Gupta, 2005. A Textbook of Machine Design, 14th ed. S. Chand and Company Limited, New Delhi.

[9] New, M. B., 1987. Feed and feeding of fish and shrimp, ADCP/REP/87/26, FAO/UNDP, Rome.

[10] Shigley, J. E. and C. R. Mischike, 2001. Mechanical engineering design, 6th ed. McGraw-Hill Publication, New York.

[11] Winrock International, 1992. Assessment of Animal Agriculture in SubSaharan Africa. Mprrilton. USA. Winrock International, pp: 20.

[12] Zegeye Yigezu, 2003. Challenges and opportunities of livestock marketing in Ethiopia. In Proceedings of The 10 th annual conference of Ethiopian Society of Animal Production (ESAP), 22-24 August 2002 held in Addis Ababa, Ethiopia, pp: 47-54.

\section{AUTHORS}

First Author - Gosa Bekele, BSc. in Agricultural Engineering and Mechanization and MSc. in Agricultural Machinery Engineering, email gosaagem@gmail.com

Correspondence Author - Gosa Bekele, email gosaagem@gmail.com, contact number +251912263915 